\title{
Effect of Monetary Policy on Commercial Banks Across Different Business Conditions
}

\author{
Syed M. Harun \\ Texas A\&M University-Kingsville, USA \\ M. Kabir Hassan \\ University of New Orleans, USA \\ Tarek S. Zaher \\ Indiana State University, USA
}

The objective of the paper is to investigate whether the stock price reactions of commercial banks to monetary policy actions are dependent on the state of the economy. The results indicate that monetary policy actions have asymmetric effects on the returns of commercial banks across different monetary policy and business environments. The asymmetric effects can primarily be attributed to the asymmetric effects of monetary policy on discount rates across different monetary and business environments. We also observe that the impact of monetary policy on the returns of commercial banks is affected by bank-specific characteristics. Bank size, leverage and profitability play an important role in explaining the cross-sectional variation in bank returns as a result of monetary policy changes. We find that cross-sectional bank-specific characteristics affect the bank returns asymmetrically as a result of monetary policy changes across different business conditions. The results suggest that the effectiveness of monetary policy depends on the states of the economy (JEL: E52, E58, G14, G21).

Keywords: Monetary policy, commercial bank, business condition.

\section{Introduction}

The interest rate channel of monetary transmission mechanism emphasizes that the changes in monetary policy first affect the bank

\footnotetext{
* The authors would like to thank the anonymous referee and the editor for valuable comments and suggestions on an earlier version of the paper. The authors would also like to thank Kenneth Kuttner for providing data used in the paper. Thanks are also due to Ozer Erdem for assistance in data collection.
}

(Multinational Finance Journal, 2005, vol.9, no.1/2, pp. 99-128)

(C) Multinational Finance Society, a nonprofit corporation. All rights reserved. DOI: $10.17578 / 9-1 / 2-5$ 
lending rates and short-term interest rates. These changes are then transmitted to long-term interest rates that then affect business investments and consumer spending. Commercial banks play an important role in the financial system because they can solve the asymmetric information problem in the credit market. According to the credit view of monetary transmission mechanism (specially the bank lending channel), monetary policy affect bank deposits and loans and in turn affect business investment and consumer spending. ${ }^{1}$ The bank-lending channel of the credit view implies that the changes in monetary policy affect both the cost of bank funds and the profitability of the banks. Because of the importance of commercial banks in the monetary transmission mechanism, banks continue to receive special attention from researchers.

Interest rate sensitivity of commercial bank stock returns is widely documented in empirical literature. ${ }^{2}$ The overwhelming evidence suggests that bank equity returns are inversely related to interest rate changes. The impact of monetary policy actions on commercial bank equity returns has also been investigated. ${ }^{3}$ The evidence points to an inverse relationship between an interest-rate based monetary policy indicator (federal funds rate and discount rate) and bank equity returns.

The objective of the paper is to investigate whether the observed stock price reaction of commercial banks to monetary policy actions are dependent on the stance of monetary policy and the state of the economy. In particular, the paper examines the sensitivity of commercial bank stock returns across different monetary policy environments and business conditions. The central focus of the paper is on whether the effects of monetary policy actions on the returns of commercial banks are symmetric across different monetary policy environments and business conditions. We also try to identify the source of the differential impact of monetary policy across different states of the economy. We explore whether discount rate proxies or the expected cash flow proxies are causing the differential effect of monetary policy

1. For a comprehensive discussion of the monetary transmission mechanism, see the papers in the "Symposia on the Monetary Transmission Mechanism" in the Journal of Economic Perspectives, Fall 1995, vol. 9, no. 4, pp. 3-96.

2. For an extensive list of the empirical literature on interest rate sensitivity on bank equity returns see the references cited in Stevenson (2002).

3. See Aharony, Saunders and Swary (1986), Born and Moser (1990), Madura and Schnusenberg (2000). 
on the returns of commercial banks. Furthermore, we study whether the impact of monetary policy on the returns of commercial banks are sensitive to bank-specific characteristics such as size, leverage and profitability. We also examine whether the cross-sectional sensitivity of commercial bank returns to monetary policy changes are asymmetric across different business conditions.

This paper contributes to the growing body of literature on the relationship between monetary policy and bank stock returns in several ways. We observe that monetary policy actions have asymmetric effects on the returns of commercial banks across different monetary policy environments. We find that the returns of commercial banks are affected by the direction of surprise monetary policy changes. We present evidence that monetary policy actions asymmetrically affect the returns of commercial banks across different states of the economy. Returns of commercial banks are more sensitive to monetary policy in good business conditions compared to bad business conditions. The observed asymmetric effects of monetary policy across different business conditions can be attributed to the asymmetric effects of monetary policy on discount rates and expected cash flow proxies. Monetary policy actions primarily affect the discount rates that drive the returns of commercial banks.

We find that the impact of monetary policy on the returns of commercial banks is affected by bank-specific characteristics such as bank size, leverage and profitability. We also observe that cross-sectional bank-specific characteristics affect the bank returns (as a result of monetary policy changes) asymmetrically across different business conditions.

The findings of the paper suggest that monetary policy plays a signaling role for the commercial banks by providing them information regarding changes in discount rates. The results also strongly suggest that the impact and effectiveness of monetary policy on the returns of commercial banks depends on the state of the economy. The results suggest that monetary policy makers do and justifiably should pay close attention to the state of the business conditions while implementing monetary policies to be effective.

A review of current empirical literature is presented in section II. Section III describes the data requirements. The tests for the asymmetric effect of monetary policy on the returns of commercial banks across different monetary policy and business environments are presented in section IV. The causes behind the observed differential effect of 
monetary policy across different business conditions are examined in section V. Section VI presents the cross-sectional tests for the asymmetric effects of monetary policy changes across different business conditions. Section VII presents the summaries of the main conclusions of the paper.

\section{Review of Empirical Literature}

Monetary policy actions can affect stock price movements if new information is revealed by the policy changes and if the new information affects either future cash flows or the discount rate or both. Monetary policy affects interest rates, which in turn can affect the cost of borrowing for corporations. Monetary policy can also provide signals about the future direction of the economy by providing information about future growth prospects or inflation, and therefore expected future cash flows. Given the importance of monetary policy, it is not surprising that investors and analysts in the stock market and the financial press closely watch the actions taken by the Federal Reserve Bank. A number of studies document the impact of monetary policy on stock and bond returns. Jensen, Mercer and Johnson (1996) observe that monetary policy actions have a significant effect on stock and bond returns. Patelis (1997) observes that monetary policy can predict stock returns over long horizons. Thorbecke (1997) observes that monetary policy shocks have similar effects across industries and that the returns on small firms are significantly affected by the policy shock. Park and Ratti (2000) observe that contractionary monetary policy shocks cause significant negative movements in inflation and expected real stock returns.

Interest rate sensitivity of commercial bank equity returns has received special attention from researchers due to the importance of commercial banks in the monetary transmission mechanism. Financial intermediaries, especially banks are exposed to interest rate risk because they engage in asset transformation function by lending long and borrowing short. The mismatched asset-liability structures make bank stock returns more exposed to interest rate surprises than other types of firms. Flannery and James (1984), Bae (1990), Choi, Elyasiani and Kopecky (1992), Mansur and Elyasiani (1995) among others observe negative relation between bank equity returns and market interest rates.

Several studies document the relationship between changes in 
monetary policy and market interest rates. Roley and Troll (1984), Smirlock and Yawitz (1985), Cook and Hahn (1988), Dueker (1992) observe positive relation between market interest rates and discount rate while Cook and Hahn (1989) observe positive relation between federal funds target rate and the market interest rates in the 1970's. Kuttner (2001) observe that only unanticipated changes in the federal funds target rate significantly affects the Treasury bill, notes and bond markets while anticipated changes has no significant effect. Wachtel and Urich (2001) and Demiralp (2001) also observe similar results and argue that the increased transparency of the operation of monetary policy in the 1990's result in the reduced significance of anticipated policy responses. Lange, Sack and Whitesell (2001) observe that the financial markets in the 1990's are better able to anticipate monetary policy changes and adjust accordingly even before the Fed announces the policy changes. All of these studies observe that the financial market reacts significantly only to unanticipated changes in monetary policy.

Aharony, Saunders and Swary (1986) examine the effects of the 1979 change in monetary policy regime on the profitability and risk of commercial banks and observe negative relationship between bank returns and interest rate surprises as well as between bank returns and rate variability. Born and Moser (1990) document the negative relation between bank equity returns and discount rate changes. Madura and Schnusenberg (2000) document negative relation between commercial bank returns and federal funds target rate changes and observe that the sensitivity of bank equity returns depends on the direction of policy change. They find that larger banks and banks with low-capital ratios are more sensitive to changes in the federal funds target rate. Kaen, Sherman and Tehranian (1997) observe negative abnormal returns of German bank equities to changes in the Bundesbank discount rate and the Lombard rate. Stevenson (2002) observes significant stock price reaction of banks in seven non-German European countries to changes in Bundesbank discount rate.

McQueen and Roley (1993) observe that the response of the stock market to macroeconomic news is different across different business conditions. They observe that the variation in response of stock prices to economic news is mostly due to the asymmetric response of the expected cash flows across different business conditions.

Most researchers in the bank interest rate sensitivity literature employ a statistical model to identify unexpected monetary policy changes. Patelis (1997), Thorbecke (1997), Park and Ratti (2000) use 
orthogonalized shocks in a monetary VAR framework to measure monetary policy shocks. ${ }^{4}$ Aharony, Saunders, and Swary (1986) use ARIMA model. Madura and Schnusenberg (2000) use the orthogonalized shock to the stock market return by the federal funds rate. On the other hand, Kuttner (2001) constructs a market-based measure of unexpected changes in monetary policy using the data from the federal funds futures market. This is the only study that uses a market-based measure of unexpected monetary policy changes as opposed to the statistical model based measures.

\section{Data}

For the purpose of this paper, we use data spanning from June 1989 to December 2000. The 1989-2000 period is interesting for several reasons. First, it enables us to use the data on unanticipated changes in federal funds target rate. The unanticipated changes in federal funds target rate is calculated using the federal funds futures market data. Second, these are the Greenspan years (Alan Greenspan became the Fed Chairman in 1987). It is widely believed that the operation of monetary policy under Greenspan has been more effective and that the Fed paid more attention to the stock market. Consequently the stock market also paid more attention to the monetary policy. Third, the U.S. stock market enjoyed unprecedented growth in this period and observed only moderate inflation. The Fed is given a lot of credit for that. Therefore, the effect of monetary policy on the stock market in this period deserves special attention (Mankiw,[2001]).

To form the portfolio of commercial banks, we use 1987 Standard Industry Classification (SIC) codes. ${ }^{5}$ We obtain the returns (both

4. See Christiano, Eichenbaum and Evans (1999) for a review of measuring monetary policy shocks in a VAR framework. See Rudebusch (1998) and Cochrane (1998) for a critique of the method.

5. CRSP database utilizes 1987 SIC codes to identify industry groups for individual firms. However, CRSP does not actively assign SIC codes to the firms. CRSP obtains NYSE and AMEX SIC codes from FT Interactive Data (formerly Interactive Data Services), and obtains NASDAQ SIC codes directly from the NASDAQ exchange. Both data providers refer to SEC documents as SIC code sources. SIC codes can be useful for rough groupings of industries. Beyond that, they should be used with caution - because they are not assigned or reviewed with a strict procedure by any government agency. Most large companies belong in multiple SIC codes and they change over time. After the initial SIC code assignment when 
equally-weighted and value-weighted) of all the firms included in the portfolio (defined on the basis of SIC codes) from the CRSP database. Since the results are qualitatively similar, we report only the results using equally weighted portfolio returns. The portfolio of commercial banks (SIC code 602) includes 863 nationally and state chartered commercial banks.

Bernanke and Mihov (1998) observe that the actual federal funds rate is a reasonably good indicator of monetary policy because it is sensitive to the shocks in the supply of bank reserves. They argue that the Fed has implemented monetary policy changes through open market operations in the federal funds market over the last 30 years. Therefore, the federal funds rate can be used as an indicator of monetary policy over monthly or longer horizon. Kuttner (2001) uses federal funds futures rates to identify monetary policy surprises and decomposes the federal funds target rate changes into anticipated and unanticipated components using information available from the federal funds futures market. ${ }^{6}$ The advantage of using the federal funds futures prices is that it is the only market-based proxy available for Fed policy expectations. However, the disadvantage of using futures data is that it limits the analysis to the post-1989 period because the federal funds futures market was established in 1989. Kuttner provided us the data of the anticipated and unanticipated changes in the federal funds target rate. To our knowledge, no studies in the bank stock return sensitivity literature have used any market-based proxy for monetary policy actions. We employ the only market-based proxy available to measure unexpected monetary policy actions in the paper to assess the impact of monetary policy actions on the returns of commercial banks.

The data on federal funds target rate is collected from the Federal Reserve Bank of New York while the federal funds rate and discount rate data are collected from the Federal Reserve Bank of St. Louis. Based on the history of the operating policy regimes of the Fed, we use the federal funds target rate and the discount rate to identify 'easy' and 'tight' monetary policy environments. The advantage of our approach

a company goes public, no government agency ever looks at that code or the company again - quite often a company reports its initial SIC code forever. Cases have been observed in which companies would have obsolete SIC codes from the 1972 coding scheme in their SEC filings from the early 1990's.

6. See Kuttner (2001) for details. 
is that we use the information contained in both the discount rate and the federal funds target rate and take into account the history of the Fed's different operating policy procedure regimes. ${ }^{7}$ The monetary policy environments are defined as easy (tight) if the relevant policy tool decreases (increases). The relevant policy tool for the Fed is the federal funds target rate for the federal funds rate targeting periods (November 1987 and December 2000).

We identify business conditions using three different approaches. First, we identify the bull and bear markets by examining the Dow Jones Industrial Average (DJIA) and the Standard and Poor's 500 index returns. The standard industry practice is to define a bull (bear) market if the broad stock market index increases (decreases) by a certain percentage (generally in excess of 15-20 percent) from the most recent low (high) level. To identify the bull and bear markets, we identify all the instances where both the S\&P 500 and DJIA went up (down) by at least 15 percent from the previous low (high) level. By using the two most widely used stock market indices, we avoid over-identifying bull and bear markets. We observe that not all 15 percent changes in the indices qualify as a bull/bear market but are sometimes large market 'corrections', either because those are quickly reversed or other indices do not move much. We also take into account the changes in the CRSP value weighted and equal weighted indices and the NASDAQ index. We observe that the bear markets in the sample period are short-lived compared to bull markets in general. We observe 3 bear markets in the 1990 's. Bear markets in the 1990's are very short-lived compared to other bear markets.

The classification of the bull and bear markets is an indication of the conditions of the stock market in general. However, these may not accurately reflect overall economic conditions. To classify the economy in different states, another choice is to use the widely accepted National Bureau of Economic Research (NBER) business cycles dates. NBER defines a recession as "a period of significant decline in total output, income, employment, and trade, usually lasting from six months to a year, and marked by widespread contractions in many sectors of the economy". ${ }^{8}$ Although NBER business cycles are widely accepted, there

7. For a discussion on the relationship between discount rate and the federal funds rate in different operating policy regimes of the Federal Reserve Bank, see Bosner-Neal, Roley and Sellon (1998), and Madura and Schnusenberg (2000).

8. The definition and the NBER recession dates are available from the NBER website 
are several problems associated with it in using it as a guide to economic states of the economy. First, NBER expansions and recessions (as well as bull and bear markets) classify the direction of economic activity rather than the level. Second, the NBER business cycle dating committee does not determine the start or end of a recession until after at least six months beyond the peak date. ${ }^{9}$

To adjust for these problems, we also employ the McQueen and Roley (1993) method to identify the business conditions. This classification scheme uses the seasonally adjusted industrial production index of all items $(1992=100)$ to identify the high, medium and low states of the economy. We estimate a trend in the industrial production index by regressing the log of the industrial production index on a constant and a time trend. We then identify an upper bound and a lower bound of the industrial production index by adding and subtracting a constant from the trend. If the actual log of industrial production index is above the upper bound, we identify it as a "high" economic state, and if it is below the lower bound, we identify it as a "low" economic state. If the actual log of the industrial production index lies within the upper and the lower bound, we identify the period as a "medium" economic state. ${ }^{10}$

From the three different schemes of identifying the business conditions, we observe several interesting facts. First, a bear market precedes every recession. Second, the majority of bear markets start while the economy is at high states and the majority of bull markets start while the economy is at low states. The observations seem to confirm the idea that bear markets are good predictors of slowdowns in industrial production and recessions.

\section{Effect of Monetary Policy Actions on Banks}

\section{A. Effect of Surprise Monetary Policy Actions}

The standard approach in the finance literature showing a link between

at http://www.nber.org.

9. NBER has even taken as long as 21 months to announce the beginning or the end of a recession. For example, March 1991 trough wasn't announced until December 22, 1992.

10. See McQueen and Roley (1993) for details on the method. 
stock returns and monetary policy indicators is regression analysis. The regression coefficients of the monetary policy indicator variables should be significant in explaining the stock returns, if monetary policy affects stock returns. The explicit incorporation of the monetary policy indicators should also improve the explanatory power of the regression if monetary policy is an important determinant of the stock market returns. Using monthly data from June 1989 to December 2000, we calculate the unconditional return sensitivity of the commercial bank portfolios by applying the following model:

$$
R_{p t}=\gamma_{0}+\gamma_{1} * R_{m t}+\gamma_{2} * U F F T_{t}+e_{t},
$$

where $R_{p t}$ is the equally weighted portfolio return on month $t ; R_{m t}$ is the $\mathrm{S} \& \mathrm{P} 500$ index return on month $t ; U F F T_{t}$ is the unanticipated changes in the federal funds target rate in month $t$. Applying ordinary least squares (OLS) estimation method to this model results in consistent estimates of the coefficients and standard errors in the absence of heteroskedasticity (Judge et.al.,1988). However, the variance of coefficient estimates, standard errors and the associated $t$-statistics are calculated using White's (1980) heteroskedasticity consistent estimator to take into account possible heteroskedasticity.

While the impact of monetary policy on commercial bank stock return is well documented, most of the previous studies assume that the investor's response to monetary policy is the same over different monetary policy environments or the states of the economy. However, if the monetary policy environments or the phases of business environments provide useful information about the equity discount rates and expected cash flows, we expect the investor's reaction to monetary policy changes to have different effect on the returns of commercial banks over different stages of the monetary policy environments and business cycle.

To examine whether the direction of the surprise monetary policy changes and the different monetary policy environments have different impacts on the stock returns of commercial banks, we estimate the conditional responses of the portfolio returns to monetary policy actions across different monetary policy environments using the following models: ${ }^{11}$

11. McQueen and Roley (1993) employed a similar approach in examining the impact of macroeconomic news on stock prices across different states of the business condition. 


$$
\begin{aligned}
& R_{p t}=\alpha_{0}+\alpha_{1}^{*} R_{m t}+\alpha_{2}\left(P_{t}^{*} U F F T_{t}\right)+\alpha_{3}\left(N_{t}^{*} U F F T_{t}\right)+e_{t} \\
& R_{p t}=\alpha_{0}+\alpha_{1}^{*} R_{m t}+\alpha_{2}\left(E_{t}^{*} U F F T_{t}\right)+\alpha_{3}\left(C_{t}^{*} U F F T_{t}\right)+e_{t},
\end{aligned}
$$

where $P_{t}$ and $N_{t}$ are dummy variables reflecting positive and negative surprises in monetary policy. $E_{t}$ and $C_{t}$ are dummy variables reflecting easy and tight monetary policy environments. The advantage of using the dummy variables this way is that the coefficients $\left(\alpha_{2}\right.$ and $\left.\alpha_{3}\right)$ directly and simultaneously estimate the effect of the direction of monetary policy changes across different monetary policy environments on the returns of commercial banks.

Over the 1990's, the operation of monetary policy has become more transparent. As a result, we observed stock markets movements in anticipation even before the FOMC announces its' policy directives. If the announced policy is in line with the stock market's expectation, the market does not move much after the actual announcement because investors have already discounted the anticipated changes and incorporated the information into stock prices. On the other hand, unanticipated changes in monetary policy significantly move the market, as rational investors only react to new information in an efficient market. Any unanticipated change in monetary policy actions is new information and investors will react to the new information. The stock price will change as a result of the arrival of new information in the market. Positive policy surprises - larger than expected value of the federal funds target rate (defined as larger than expected reductions or smaller than expected increases) can be identified as a policy stance more expansionary (or less contractionary) than expected. We expect the market to be pleasantly surprised by positive surprises in policy. On the other hand, negative surprises - smaller than expected values of the federal funds target rate (defined as smaller than expected reductions or larger than expected increases) can be identified as a policy stance less expansionary (or more contractionary) than expected. We expect the market to be unpleasantly surprised by negative policy surprises. We expect the market to react more to a better than expected expansionary move (positive policy surprises) compared to a worse than expected expansionary move (negative policy surprises) by the Fed.

Table 1 displays the regression results for the entire sample period from June 1989 December 2000 using the unanticipated changes in the federal funds rate as the monetary policy indicator. We observe that the coefficients of the market return $\left(R_{m t}\right)$ variable are all positive and 


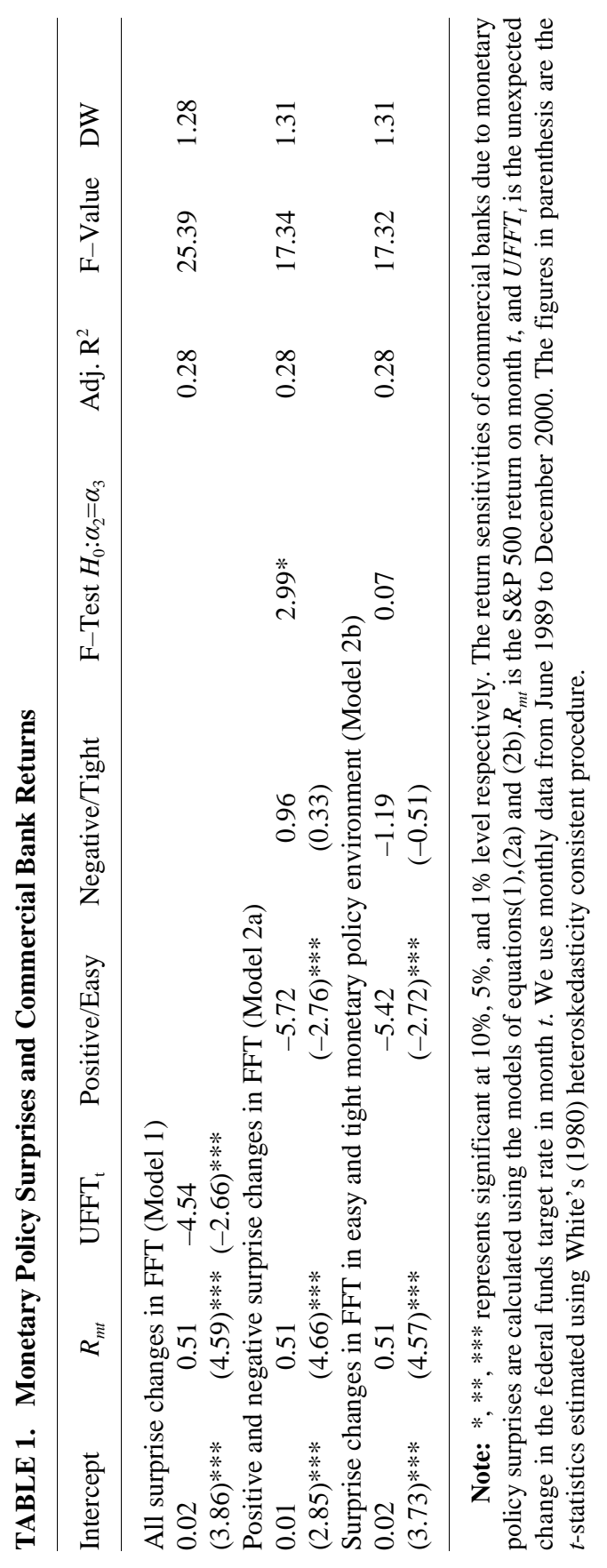


significant. As expected, the market return is a highly significant determinant of the portfolio returns of commercial banks. The coefficients of the unanticipated changes in the federal funds target rate $\left(U F F T_{t}\right)$ variable are all negative and significant: the returns of commercial banks are highly negatively related to the unanticipated changes in the federal funds target rate. These results are consistent with the earlier studies that the returns of commercial banks and changes in an interest rate-based monetary policy indicator are inversely related. The high $F$-values suggest that the coefficients of the two variables are jointly significant, and the Durbin-Watson $d$-statistics suggest the absence of autocorrelation in the regressions.

We observe that positive monetary policy surprises have significant impact on bank returns while negative monetary policy surprises do not significantly affect the returns of commercial banks. Positive monetary policy surprises can be interpreted as good news for the market while negative monetary policy surprises can be interpreted as bad news for the market. We observe that commercial banks react significantly to good news about monetary policy (positive monetary policy surprises) but do not react significantly to bad news (negative surprises). The 1990's are characterized by high growth and low inflation. The bad news about monetary policy did not automatically translate into an indication of deterioration in the high growth and low inflation situation, in the absence of subsequent information regarding the deterioration of the economy. So, any negative effect of the bad news regarding monetary policy on the stock market during the month may have been offset by the subsequent release of other economic news (mostly good) within the month. On the other hand, good news about monetary policy with subsequent confirmation about the strength of the economy (from the subsequent release of other economic news) within the month results in significant effects on the stock market. The results are consistent with the signaling role of monetary policy and possibly show investors' confidence in the Fed's handling of the economy in the 1990's.

The results reported in table 1 also show that monetary policy environments asymmetrically affect the returns of commercial banks. We observe that the results are significant in easy monetary policy environments but not in the tight monetary policy environments. We also observe that the coefficients of unexpected changes in the federal funds target rate are higher in absolute magnitude in easy monetary policy environments compared to tight monetary policy environments. 
TABLE 2. Effect of Monetary Policy Surprises Across Different Business Conditions

\begin{tabular}{|c|c|c|c|}
\hline \multicolumn{4}{|c|}{ Surprise changes in FFT in bull and bear market (Model 3a) } \\
\hline Bull & \multicolumn{2}{|c|}{ Bear } & $F-\operatorname{Test}\left(H_{0}: \alpha_{2}=\alpha_{3}\right)$ \\
\hline $\begin{array}{l}-4.53 \\
(-2.66) * * *\end{array}$ & \multicolumn{2}{|c|}{$\begin{array}{l}-8.76 \\
(-0.17)\end{array}$} & 0.007 \\
\hline \multicolumn{4}{|c|}{ Surprise changes in FFT in economic expansion and recession (Model 3a) } \\
\hline Expansion & \multicolumn{2}{|c|}{ Recession } & F-Test $\left(H_{0}: \alpha_{2}=\alpha_{3}\right)$ \\
\hline $\begin{array}{l}-3.80 \\
(-2.24)^{* *}\end{array}$ & \multicolumn{2}{|c|}{$\begin{array}{l}-8.95 \\
(-0.85)\end{array}$} & 0.245 \\
\hline \multicolumn{4}{|c|}{$\begin{array}{l}\text { Surprise changes in FFT in high, medium and low industrial production growth } \\
\text { (Model } 3 \mathrm{~b} \text { ). }\end{array}$} \\
\hline IP High & IP Medium & IP Low & $F$-Test $\left(H_{0}: \beta_{2}=\beta_{4}\right)$ \\
\hline $\begin{array}{c}6.22 \\
(0.45)\end{array}$ & $\begin{array}{l}2.37 \\
(0.57)\end{array}$ & $\begin{array}{l}-5.09 \\
(-2.82)^{* * *}\end{array}$ & 0.703 \\
\hline
\end{tabular}

Note $^{*}, * *, * * *$ represents significant at $10 \%, 5 \%$, and $1 \%$ level respectively. The conditional return sensitivities are calculated using the models of equations ( $3 a$ ) and (3b). We use monthly data from June 1989 to December 2000. The figures in parenthesis are the t-statistics estimated using White's (1980) heteroskedasticity consistent procedure.

The results support the hypothesis that monetary policy has asymmetric effects across different monetary policy environments. We find that policy changes in easy monetary policy environments have more pronounced effects on the returns of commercial banks compared to the policy changes in tight policy environments.

\section{B. Bank Returns Across Different Business Environments}

To examine whether different business environments have different impacts on the stock returns of commercial banks we estimate the conditional responses of the portfolio returns to monetary policy actions across different business conditions using the following models:

$$
\begin{gathered}
R_{p t}=\alpha_{0}+\alpha_{1}^{*} R_{m t}+\alpha_{2}\left(G_{t}^{*} U F F T_{t}\right)+\alpha_{3}\left(B_{t}^{*} U F F T_{t}\right)+e_{t} \\
R_{p t}=\beta_{0}+\beta_{1}{ }^{*} R_{m t}+ \\
\beta_{2}\left(H_{t}^{*} U F F T_{t}\right)+\beta_{3}\left(M_{t}^{*} U F F T_{t}\right)+\beta_{4}\left(L_{t}^{*} U F F T_{t}\right)+e_{t}
\end{gathered}
$$


where, $G_{t}$ is a dummy variable, which takes a value of 1 if month $t$ is in bull market/economic expansion and zero otherwise; $B_{t}$ is a dummy variable, which takes a value of 1 if month $t$ is in bear market/recession and zero otherwise; $H_{t}$ is a business condition dummy variable, which takes a value of 1 if month $t$ is in high state of industrial production and zero otherwise; $M_{t}$ is a business condition dummy variable, which takes a value of 1 if month $t$ is in medium state of industrial production and zero otherwise; and $L_{t}$ is a business condition dummy variable that takes a value of 1 if month $t$ is in low state of industrial production and zero otherwise. The advantage of using the dummy variables this way is that the coefficients ( $\alpha_{2}$ and $\alpha_{3}$ in model (3a) and $\beta_{2}, \beta_{3}$ and $\beta_{4}$ in model (3b)) directly and simultaneously estimate the effect of monetary policy in different business conditions on the returns of commercial banks.

Table 2 presents the conditional responses of the commercial bank returns to monetary policy across different business conditions using monthly data from June 1989 to December 2000 using the unanticipated changes in the federal funds target rate as the indicator of monetary policy. The results suggest that monetary policy has asymmetric effect across different business conditions. We observe that the return sensitivity of the commercial banks to monetary policy is significant in bull markets, in economic expansions, and in low states of economic activity. We observe that the coefficients of the monetary policy indicator variables are larger in absolute magnitude in bear markets compared to those in bull markets for commercial banks. The results indicate that monetary policy has a significantly larger effect in bull markets compared to bear markets. We also observe that the magnitude of the effect of monetary policy on the returns of commercial banks is larger in recessions compared to expansions. It appears from the results that monetary policy has more significant effect on the commercial banks' returns in good state of the economy as opposed to bad states, although monetary policy seems to affect the portfolio returns in larger magnitude in bad times as opposed to good times.

From table 2, we observe that the effect of monetary policy surprises on the returns of commercial banks is significant in bull markets but not in bear markets, in economic expansions but not in recessions. The results imply that the returns of commercial banks are more responsive to monetary policy in the good state of the economy. Interestingly however, we observe that surprise changes in monetary policy significantly affect the returns or commercial banks in the low state of the economy but not in the high or medium state of the economy. The 
Fed has traditionally followed an easy monetary policy to promote higher growth in the times of economic downturns, while it has followed a tight monetary policy to contain higher inflation in times of economic upswings. An easy monetary policy environment may be interpreted as providing good news (rate reduction) in bad times (economic downturns) while a tight policy may be interpreted as bad news (rate hike) in good times (economic upswing). The observed results may be a manifestation of the fact that investors' react more to bad news in good times compared to good news in bad times. ${ }^{12}$ Another possibility in explaining the asymmetric effect of monetary policy on the returns of commercial banks across different monetary policy environments is that the interest rate on liabilities may adjust faster than the interest rates on assets for commercial banks in response to a decrease in the federal funds rate, leading to a significant policy response of commercial banks in the tight monetary policy period. The asymmetric effect may also be the result of a higher elasticity of asset demand for the commercial banks in response to an increase in interest rates compared to a decrease in interest rates.

\section{Event Study Evidence}

Event study is a standard approach in the finance literature to capture the stock price response of any announcement. We apply the event study method to evaluate the announcement effect of monetary policy actions on the returns of various commercial banks. One advantage of event study methodology is that we are able to concentrate on the specific dates when the monetary policy changes are announced. We estimate the following model including data only for the announcement days:

$$
R_{p t}=\pi_{0}+\pi_{1}^{*} U F F T_{t}+e_{t}
$$

where $R_{p t}$ is the equally weighted portfolio return on day $t$; and $U F F T_{t}$ is the unexpected changes in the federal funds target rate on day $t$. We estimate the conditional responses of the portfolio returns to monetary policy across different business conditions using the following models: ${ }^{13}$

12. McQueen and Roley (1993) show that good news about economic activity in good states of the economy may be bad news for the stock market.

13. Models (4), (5a) and (5b) are also estimated including the S\&P 500 market return $\left(\mathrm{R}_{\mathrm{mt}}\right)$. The results being qualitatively similar, are not reported in the paper. 


$$
\begin{gathered}
R_{p t}=\alpha_{0}+\alpha_{1}\left(G_{t}^{*} U F F T_{t}\right)+\alpha_{2}\left(B_{t}^{*} U F F T_{t}\right)+e_{t} \\
R_{p t}=\beta_{0}+\beta_{1}\left(H_{t}^{*} U F F T_{t}\right)+\beta_{2}\left(M_{t}^{*} U F F T_{t}\right)+\beta_{3}\left(L_{t}^{*} U F F T_{t}\right)+e_{t},
\end{gathered}
$$

where $G_{t}$ is a dummy variable, which takes a value of 1 if month $t$ is in bull market/economic expansion and zero otherwise; $B_{t}$ is a dummy variable, which takes a value of 1 if month $\mathrm{t}$ is in bear market/recession and zero otherwise; $H_{t}$ is a business condition dummy variable, which takes a value of 1 if month $t$ is in high state of industrial production and zero otherwise; $M_{t}$ is a business condition dummy variable, which takes a value of 1 if month $t$ is in medium state of industrial production and zero otherwise; and $L_{t}$ is a business condition dummy variable that takes a value of 1 if month $t$ is in low state of industrial production and zero otherwise. The advantage of using the dummy variables this way is that the coefficients ( $\alpha_{1}$ and $\alpha_{2}$ in model (5a) and $\beta_{1}, \beta_{2}$ and $\beta_{3}$ in model (5b)) directly and simultaneously estimate the effect of monetary policy in different business conditions on the returns of commercial banks.

We are interested in estimating the announcement effect of surprise monetary policy actions and we confine our analysis to the post-1989 period, because of data availability regarding surprise monetary policy changes. There are 44 announcements of the federal funds rate change in the sample period from March 1989 to December 2000. We estimate models (4) using the data on unanticipated changes in the federal funds target rate as the monetary policy indicator for this period. The announcement day responses of the portfolio returns due to federal funds surprises are presented in table 3 . The variance of coefficient estimates, the standard errors and the associated t-statistics are calculated using White's (1980) heteroskedasticity consistent estimator to take into account possible heteroskedasticity. We observe that the announcement effect of monetary policy surprises on the returns of commercial banks is negative and significant.

An interesting sample would consist of those days on which the investors thought there might be a target rate change, regardless of whether a change actually occurred. It is impossible to know all such dates, but an interesting subset consists of FOMC meeting dates. There are 88 FOMC meeting dates between June 1989 and December 2000. Twenty-four of the 44 target rate changes in the sample are associated with FOMC meetings, with the rest occurring in the interval between meetings. We estimate models (4), (5a) and (5b) on FOMC meeting 
TABLE 3. Effect of Monetary Policy Surprises: Event Study Evidence

\begin{tabular}{|c|c|c|c|c|}
\hline \multicolumn{5}{|c|}{$\begin{array}{l}\text { Announcement Effect of Monetary Policy Surprises. } \\
\text { Announcement effect (Model 4). }\end{array}$} \\
\hline Intercept & UFFT & Adj. $R^{2}$ & $F-$ Value & DW \\
\hline $\begin{array}{l}0.002 \\
(2.77)^{* * *}\end{array}$ & $\begin{array}{l}-0.073 \\
(-2.06)^{* *}\end{array}$ & 0.093 & 5.410 & 2.108 \\
\hline
\end{tabular}

Announcement Effect of Monetary Policy Surprises across Different Business Conditions.

Announcement effect across bull and bear markets (Model 5a).

$\begin{array}{lcc}\text { Bull } & \text { Bear } & F \text {-Test }\left(H_{0}: \alpha_{1}=\alpha_{2}\right) \\ -0.074 & 0.095 & 2.010 \\ (-2.06)^{* *} & (0.90) & \end{array}$

Announcement effect across expansion and recessions (Model 5a).

Expansion Recession $\quad F$-Test $\left(H_{0}: \alpha_{1}=\alpha_{2}\right)$

$\begin{array}{lll}-0.083 & 0.004 & 0.333\end{array}$

$(-2.30)^{* *} \quad(0.02)$

Across high, medium and low industrial production growth (Model 5b).

$\begin{array}{lccc}\text { IP High } & \text { IP Medium } & \text { IP Low } & F-\text { Test }\left(H_{0}: \beta_{1}=\beta_{3}\right) \\ -0.304 & -0.106 & -0.054 & 6.258^{* *} \\ (-3.21)^{* * *} & (-1.48) & (-1.52) & \end{array}$

Note: *,**,*** represents significant at $10 \%, 5 \%$, and $1 \%$ level respectively. We use daily announcement day data for the period March 1989 to December 2000. The figures in parenthesis are the t-statistics estimated using White's (1980) heteroskedasticity consistent procedure.

dates and observed similar results (not reported) although the coefficients are smaller in magnitude and less significant. The difference in the results is likely due to having a smaller number of target rate changes in the sample ( 24 of the 44 changes took place on FOMC meeting dates) which precludes 20 non-meeting date target rate changes, many of which contained a large surprise element. Moreover, investors expect monetary policy actions on FOMC meeting dates and so the surprise element in policy is smaller on FOMC meeting dates compared to non-meeting dates.

We estimate models (5a) and (5b) with unexpected changes in the federal funds target rate on the announcement days of the change in the target rate. The results are also presented in table 3. In the sample period (March 1989 - December 2000) there are 44 announcements of federal funds target rate changes of which only one fell in a bear market (rendering the inference unusable), and 7 fell in a recession. We observe that the bank returns are significantly affected by monetary policy in 
bull markets, in economic expansion and in high states of economic activity for the commercial banks. The results generally support the idea that commercial banks are more responsive to monetary policy announcements in better business condition.

In a variation of the standard event study methodology, we also estimate the portfolio return sensitivities due to federal funds surprises using daily data from March 1989 to December 2000. We estimate models (4), (5a) and (5b) using daily data where the unanticipated change in the federal funds target rate variable $\left(U F F T_{t}\right)$ is non-zero on only 44 days (on the days the federal funds target rates are actually changed) but are zero on the rest of the days, because there are 44 changes of the federal funds target rate during this period. We observe qualitatively similar results.

\section{Discount Rates or Expected Cash Flows?}

Monetary policy actions can affect stock price movements if the policy actions affect either future cash flows or the discount rate or both. In this section, we attempt to measure the response of equity discount rates and expected cash flows to changes in monetary policy across different monetary policy environments and business conditions. We consider several proxies for discount rates and expected cash flows. The discount rate proxies include term premium, default premium and quality premium. We define term premium (TERM) as the difference between 10-year Treasury bond and 3-month Treasury bill rates; default premium (DEF) as the difference between the Moody's Baa corporate bonds and 10-year Treasury bond yields; and quality premium (QUAL) as the difference between Moody's Baa and Aaa corporate bond yields. The expected cash flow proxies used in the paper are dividend yield (DIVYLD) defined by the total annual dividend received divided by the current price and the growth rate of industrial production (IPG).

The tests for asymmetric responses of discount rates and the expected cash flow proxies to monetary policy across different monetary policy environments and business conditions are done using the specification:

$$
Y_{t}=\alpha_{0}+\alpha_{1}\left(G_{t}^{*} U F F T_{t}\right)+\alpha_{2}\left(B_{t}^{*} U F F T_{t}\right)+e_{t}
$$




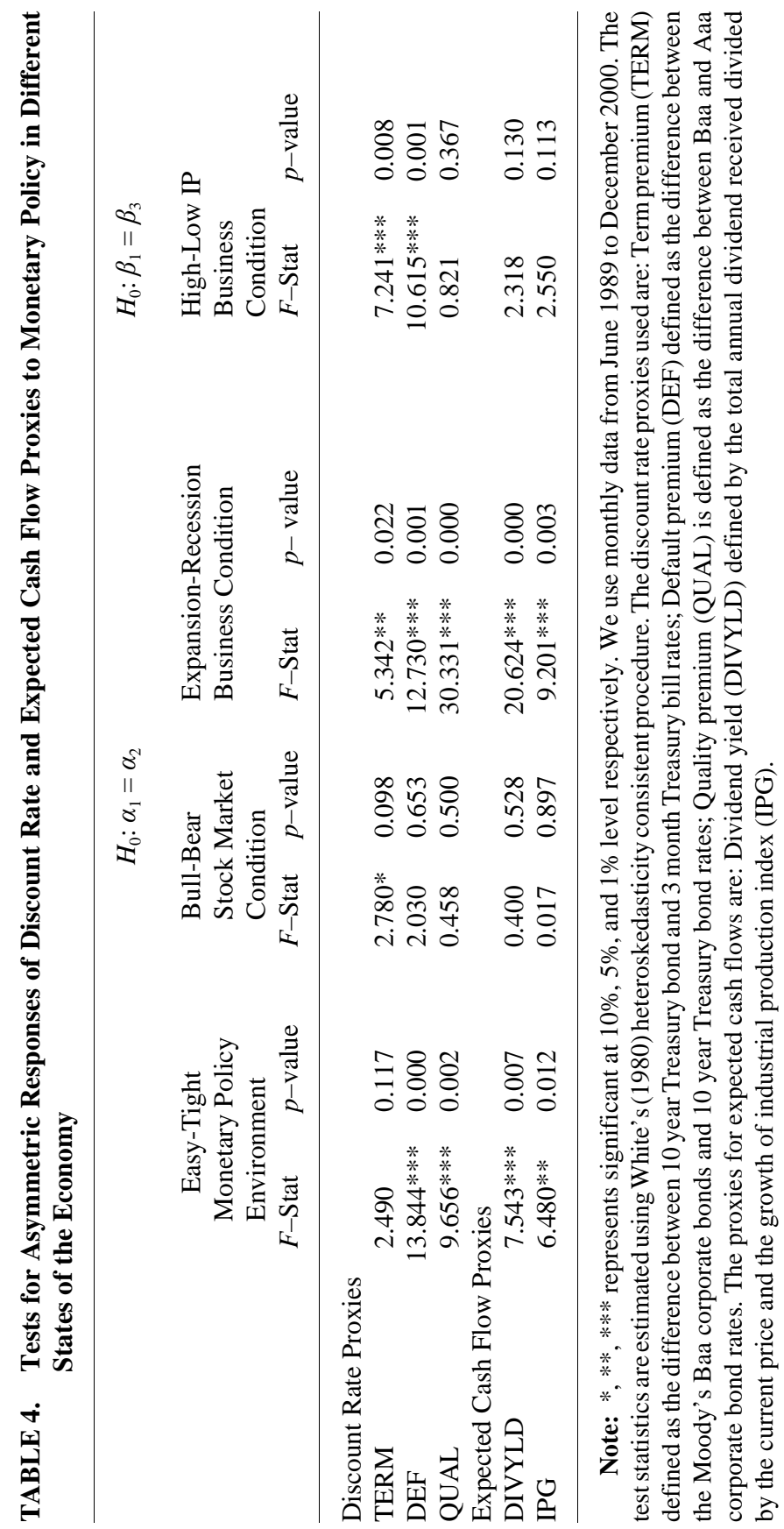




$$
Y_{t}=\beta_{0}+\beta_{1}\left(H_{t}^{*} U F F T_{t}\right)+\beta_{2}\left(M_{t}^{*} U F F T_{t}\right)+\beta_{3}\left(L_{t}^{*} U F F T_{t}\right)+e_{t}
$$

where $Y_{t}$ is the proxy for equity discount rates or the expected cash flows, $U F F T_{t}$ is the monetary policy indicator and the dummy variables reflect monetary policy environments and business conditions. $G_{t}$ is a dummy variable, which takes a value of 1 if month $t$ is in easy monetary environment/bull market/economic expansion and zero otherwise; $B_{t}$ is a dummy variable, which takes a value of 1 if month $t$ is in tight monetary environment/bear market/recession and zero otherwise; $H_{t}$ is a business condition dummy variable, which takes a value of 1 if month $t$ is in high state of industrial production and zero otherwise; $M_{t}$ is a business condition dummy variable, which takes a value of 1 if month $t$ is in medium state of industrial production and zero otherwise; and $L_{t}$ is a business condition dummy variable that takes a value of 1 if month $t$ is in low state of industrial production and zero otherwise.

Table 4 reports the $F$-statistics and the $p$-values for the null hypothesis $\left(H_{0}\right): \alpha_{1}=\alpha_{2}$ and $\beta_{1}=\beta_{3}$. The test statistics are estimated using White's (1980) heteroskedasticity consistent procedure. We conduct the tests using the unexpected changes in the federal funds target rate as the indicator of monetary policy for the period June 1989 to December 2000. The results indicate that the null hypothesis that the response of discount rate and expected cash flow proxies to monetary policy actions is the same across both easy and tight monetary policy environments can be rejected. The test statistics are significant for default and quality premiums (discount rate proxies) and dividend yield and the industrial production growth (expected cash flow proxies). The null hypothesis across bull and bear markets, however, cannot be rejected (except for the term premium). On the other hand, the null hypothesis can be rejected across expansions and recessions. We observe that the $F$-statistics are significant for term, default and quality premium (discount rate proxies) and for dividend yield and industrial production growth (expected cash flow proxies). We observe similar results across different business conditions identified by the high and low levels of industrial production. The discount rate proxies (term premium and default premium) respond differently to monetary policy surprises across high and low level of industrial production. However, the expected cash flow proxies do not seem to respond differently to monetary policy surprises across high and low levels of industrial production growth. The results support our hypothesis that the differential effect of monetary policy on the returns of investments 
companies across different monetary policy environments and business conditions are driven by the differential effect of the equity discount rates and expected cash flows.

Furthermore, we observe (results not reported in the table) that the adjusted $R^{2}$ s for the discount rate proxy models are significantly higher (over 0.30) compared to that of expected cash flow proxies (below $0.10)$. These observations suggest that the equity discount rate proxies primarily drive the differential effect of monetary policy across different monetary policy environments and business conditions.

To test whether the expected cash flow proxies take a longer time to adjust to changes in monetary policy compared to discount rate proxies, we have estimated the models (6a) and (6b) by allowing the expected cash flow proxies to be affected by monetary policy changes with a lag of one or two months. The results are similar to those observed in table 4 and are less significant. We also have done the same for the discount rate proxies and observe insignificant results.

McQueen and Roley (1993) observe that the variation of stock prices to macroeconomic news across different economic states is due to the asymmetric responses of expected cash flow proxies but they do not find significant asymmetric responses of equity discount rate proxies across different economic states. They concentrate on the types of economic news (industrial production, unemployment, trade deficit, inflation) that probably have more impact on expected cash flows as opposed to discount rates. However, we observe that monetary policy actions result in an asymmetric response of both equity discount rates and expected cash flow proxies across different business conditions. Our results suggest that the equity discount rates are more affected by monetary policy than expected cash flows across different monetary policy and business environments. The result is probably due to the fact that monetary policy changes affect discount rates more that the expected cash flows by affecting market interest rates.

\section{Cross-Sectional Tests for Asymmetric Responses of Bank Returns}

The sensitivity of the returns of commercial banks to changes in monetary policy can possibly be attributed to some bank-specific characteristics. Hanweck and Kilcollin (1984) finds that smaller banks are more exposed to interest rate risk relative to large banks and smaller 
banks have higher profitability during periods of increasing interest rates. Neuberger (1991) observes that large banks are more exposed to stock market risk than small banks. Madura and Schnusenberg (2000) observe that the cross-sectional variation in abnormal returns of commercial banks can be partially attributed to bank size and capital ratio. They observe that the returns of large banks and banks with low capital ratios are more sensitive to monetary policy changes.

In this section, we test whether the sensitivity of the commercial bank returns to bank-specific characteristics as a result of monetary policy changes are asymmetric across different business conditions. We focus on three different cross-sectional bank-specific characteristics identified by previous studies: size, leverage and profitability. We use two different measures of each of the bank specific characteristics. Bank size is measured by total asset and market value of equity. Leverage is measured by debt to total asset ratio and debt to equity ratio. Profitability is measured by return on assets (ROA) and return on equity (ROE). The cross-sectional data used in this section is collected from 2003 Compustat annual datafile. Table 5 presents the sample characteristics of the 92 commercial banks. The mean total asset of the sample banks is $\$ 39.6$ billion with a standard deviation of $\$ 60.8$ billion. The average market value of equity is $\$ 2.9$ billion with a standard deviation of about $\$ 5.0$ billion. The mean debt-total asset ratio and debt-equity ratios are 0.31 and 4.35 respectively with standard deviations of 0.16 and 1.54 respectively. The average return on equity of sample banks is $10.45 \%$ with a standard deviation of $18.21 \%$. The average return on asset is $0.92 \%$ with a standard deviation of $1.86 \%$.

The tests for the sensitivity of bank returns to monetary policy surprises due to bank-specific characteristics are done using seemingly unrelated regression (SUR). To investigate whether the return sensitivity of commercial banks to monetary policy changes are dependent on bank-specific characteristics, we divide the sample banks in each period into two different portfolios based on the bank-characteristics. For example, to examine the impact of size, we sort the sample banks every year according to their size measured by total asset or market value of equity the preceding year. Each bank portfolio represents one-half of the banks in the period under consideration: the banks below the median size are used to compute the returns of small banks while the banks above the median size are used to calculate the returns of large banks. We do the same thing with leverage and profitability ratios. The portfolio returns of these banks are 
TABLE 5. Sample Characteristics of the Commercial Banks.

\begin{tabular}{lcc}
\hline & Mean & Standard Deviation \\
\hline Total Assets (\$ millions) & 39,598 & 60,768 \\
Market Value (\$ millions) & 2,890 & 4,995 \\
Net Income (\$ millions) & 289 & 403 \\
EPS & 2.47 & 1.78 \\
Stock Price & 18.16 & 21.74 \\
ROE & $10.45 \%$ & $18.21 \%$ \\
ROA & $0.92 \%$ & $1.86 \%$ \\
Total Debt (\$ millions) & 12,595 & 9,643 \\
Debt-Total Asset Ratio & 0.31 & 0.16 \\
Debt-Equity Ratio & 4.35 & 1.54 \\
P/E Ratio & 14.05 & 15.12 \\
M/B Ratio & 1.47 & 0.95 \\
& & \\
Number of banks & 92 & \\
\hline
\end{tabular}

Note: The mean and standard deviation of the sample characteristics are calculated over the sample period (1989-2000) for all 92 banks.

used to re-estimate model (1) as a system of equations using SUR according to the following specifications:

$$
\begin{aligned}
& R_{1, t}=\alpha_{1}+\beta_{1} * R_{m t}+\varphi_{1} * U F F T_{t}+e_{1, t} \\
& R_{2, t}=\alpha_{2}+\beta_{2} * R_{m t}+\varphi_{2} * U F F T_{t}+e_{2, t},
\end{aligned}
$$

$R_{1, t}$ and $R_{2, t}$ are the bank return on month $t$ based on bank characteristics (for example, small and large banks, banks with low and high leverage ratio, banks with low and high profitability ratios). UFFT is the unanticipated changes in the federal funds target rate on month $t$. We use monthly data from June 1989 to December 2000. To investigate whether the sensitivity of bank returns to monetary policy is dependent on the cross-sectional bank-specific characteristics, we test for the differences in coefficients $\left(H_{0}: \varphi_{1}=\varphi_{2}\right)$. The test statistics are estimated using White's (1980) heteroskedasticity consistent procedure.

To test whether the sensitivity of the commercial bank returns to bank-specific characteristics as a result of monetary policy changes are asymmetric across different business conditions, we re-estimate model (3b) as a SUR system according to the following specifications: 
$R_{1, t}=\alpha_{1}+\beta_{1}^{*} R_{m t}+\gamma_{1}\left(H_{t}^{*} U F F T_{t}\right)+\kappa_{1}\left(M_{t}^{*} U F F T_{t}\right)+\delta_{1}\left(L_{t}^{*} U F F T_{t}\right)+e_{1, t}$

$R_{2, t}=\alpha_{2}+\beta_{2}^{*} R_{m t}+\gamma_{2}\left(H_{t}^{*} U F F T_{t}\right)+\kappa_{2}\left(M_{t}^{*} U F F T t\right)+\delta_{2}\left(L_{t}^{*} U F F T_{t}\right)+e_{2, t}$,

$H_{t}, M_{t}$ and $B_{t}$ are dummy variables reflecting high, medium and low levels of industrial production respectively. To examine whether the sensitivity of bank returns to monetary policy is dependent on the cross-sectional bank-specific characteristics across different business conditions, we test for the differences in coefficients $\left(H_{0}: \gamma_{1}=\gamma_{2}\right.$; and $H_{0}: \delta_{1}=\delta_{2}$ ).

The first two columns of table 6 presents the tests of whether the return sensitivity of commercial banks to monetary policy changes is dependent on bank-specific characteristics. We focus on three bank-specific characteristics: size, leverage and profitability. The estimated coefficients of the test statistics of bank size differences (small vs. large) are positive and statistically significant for both total asset and the market value of equity as a measure of bank size. The results indicate that the larger banks are more sensitive to monetary policy changes than smaller banks. The results show that bank size is a significant determinant of the cross-sectional variation in bank equity return. We also observe that the estimated coefficients of the differences in leverage ratios (low vs. high) are positive and significant. It shows that banks with higher leverage ratio are more sensitive to monetary policy changes than banks with lower leverage ratio. Madura and Schnusenberg (2000) observe that banks with high capital ratios are less sensitive to monetary policy changes. Since banks with higher leverage ratios must have lower capital ratios, our observation complements their findings. Finally, the estimated coefficients of the differences in profitability ratios (low vs. high) are negative. However, the results are statistically significant for ROA only, not for ROE. The results suggest that banks with lower profitability are more sensitive to monetary policy changes. If ROA can be interpreted as an indication of how efficiently the banks' income and assets are managed, then our results indicate that the less efficient banks are more sensitive to monetary policy changes.

The tests of whether the sensitivity of the commercial bank returns to bank-specific characteristics as a result of monetary policy changes are asymmetric across different business conditions are presented in the last four columns of table 6 . We observe that the estimated coefficients of the test statistics are positive and significant for bank size measures in the low state of business condition while the coefficients are negative 


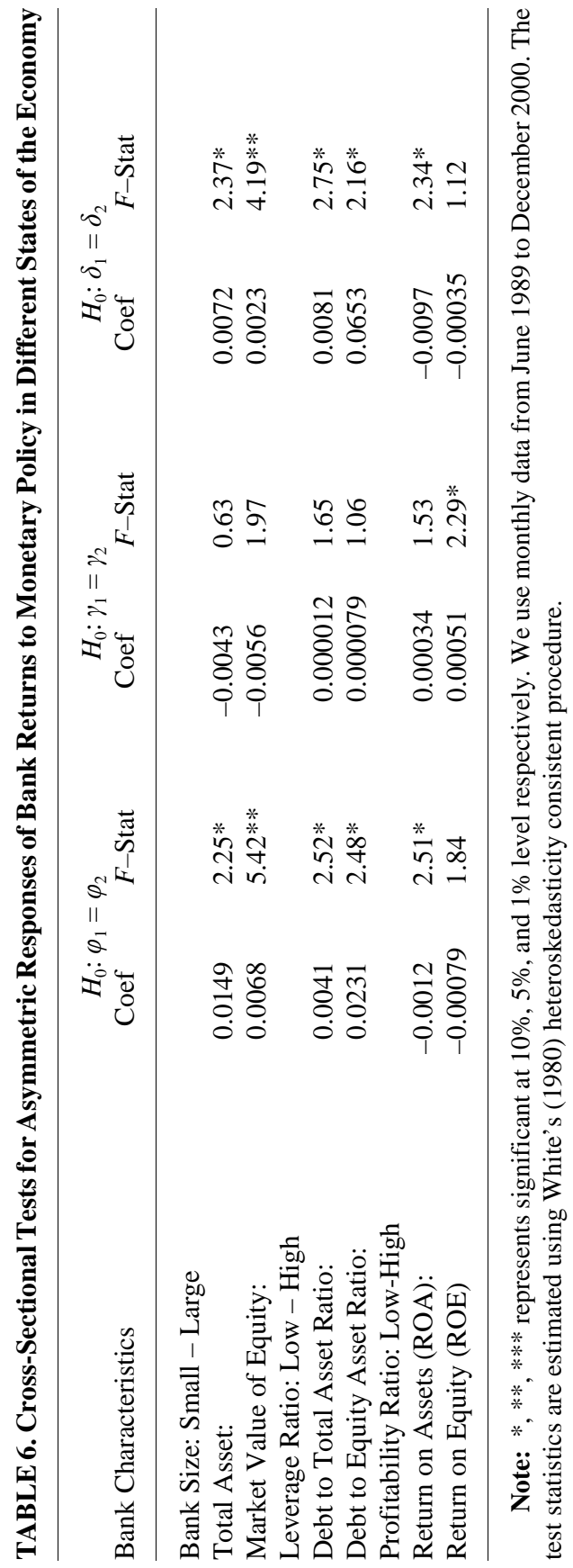


(but not statistically significant) in high states of business condition. The results indicate that the returns of larger banks are more sensitive to monetary policy changes when the economy is not performing well. But it also seems to suggest that the larger banks are less sensitive to monetary policy changes when the economy is performing well. We conclude that the sensitivity of the commercial bank returns to bank size as a result of monetary policy changes is asymmetric across different business conditions. We observe similar results for leverage and profitability ratios. With leverage ratio we observe that the test statistics are positive and significant in low states of the economy while they are smaller (closer to zero) and insignificant in good economic condition. The results suggest that the returns of highly leveraged banks are more sensitive to monetary policy changes in bad business condition but the leverage ratio does not seem to have much impact on bank returns due to monetary policy changes in good business conditions. However, we observe conflicting results with the two different measures of profitability ratios. With ROA, we find that the test statistics is negative and significant in low states of the economy while positive but insignificant in high states of the economy. The results imply that the returns of low ROA banks are more sensitive to monetary policy changes in low state of the economy but returns of high ROA banks are more sensitive in better business condition. Since high ROA results from better efficiency of income and asset management, the results indicate that less efficient banks are more sensitive to monetary policy changes in bad business environment while more efficient banks are more sensitive to monetary policy changes in better business environment. The results may be due to the fact that income potential of larger banks is high in better business environment while the income potential of smaller banks is more adversely affected in worsening business condition. However, we do not observe any asymmetric effect across different business condition with ROE and the results are only significant in better business environment. We observe that the returns of low ROE banks are more sensitive to monetary policy changes in both low and high states of the economy.

\section{Conclusion}

We find that the effects of monetary policy on the commercial banks are asymmetric across different monetary policy environments. Monetary 
policy surprises affect the returns of commercial banks significantly in easy monetary policy environment but not in tight monetary environment. The returns of commercial banks are also asymmetrically affected by the direction of surprise policy changes. The returns of commercial banks are significantly affected by positive monetary policy surprises while negative policy surprises do not seem to affect them. We also observe that monetary policy surprises affect the returns of commercial banks asymmetrically across different business conditions and the results are robust to different identification scheme of the business conditions. The evidence shows that the effect of monetary policy on the returns of commercial banks in good business conditions is significant compared to bad business conditions.

The asymmetric effect of monetary policy across different business conditions is due to the asymmetric effect of monetary policy on the discount rates and expected cash flow proxies across different business conditions. However, the effect of monetary policy on the stock returns are driven primarily by its effect through changes in discount rate proxies as opposed to expected cash flow proxies.

We observe that the impact of monetary policy on the returns of commercial banks is affected by bank-specific characteristics. Bank size, leverage and profitability play an important role in explaining the cross-sectional variation in bank returns as a result of monetary policy changes. We also observe that cross-sectional bank-specific characteristics affect the bank returns (as a result of monetary policy changes) asymmetrically across different business conditions.

The findings of the paper suggest that monetary policy plays a signaling role for the commercial banks by providing them information regarding changes in discount rates. The results also strongly suggest that the impact and effectiveness of monetary policy on the returns of commercial banks depends on the state of the economy. There is also evidence of cross-sectional variation in the impact of monetary policy on commercial bank returns due to bank-specific characteristics such as bank size, leverage and profitability. The cross-sectional variation as a result of bank-specific characteristics in bank return due to changes in monetary policy depends on the state of the economy. The results suggest that policy makers do and justifiably should pay close attention to the state of the business conditions while implementing monetary policies to be effective. 


\section{References}

Aharony, J.; Saunders, A.; and Swary, I. 1986. The effects of a shift in monetary policy regime on the profitability and risk of commercial banks. Journal of Monetary Economics 17: 363-377.

Bae, S. C. 1990. Interest rate changes and common stock returns of financial intermediaries. Journal of Financial Research 13: 71-79.

Bernanke, B.S., and Mihov, I. 1998. Measuring monetary policy. Quarterly Journal of Economics 113: 869-902.

Born, J.A., and Moser, J.T. 1990. Bank equity returns and changes in the discount rate. Journal of Financial Services Research 6: 223-241.

Bosner-Neal, C.; Roley, V.V.; and Sellon Jr., G.H. 1998. Monetary policy actions, intervention, and exchange rates: A re-examination of the empirical relationships using federal funds rate target data. Journal of Business 71: 147-177.

Choi, J.J.; Elyasiani, E.; and Kopecky, K.J. 1992. The sensitivity of bank stocks to returns to market, interest and exchange rate risks. Journal of Banking and Finance 16:983-1004.

Christiano, L.J.; Eichenbaum, M; and Evans, C. 1999. Monetary policy shocks: What have we learned and to what end? in Taylor, J.B. and Woodford, M. (Eds.) Handbook of Macroeconomics. Elsevier Science, Amsterdam, Netherlands.

Cochrane, J.H. 1998. What do the VAR's mean? Measuring the output effects of monetary policy. Journal of Monetary Economics 41: 277-300.

Cook, T., and Hahn, T. 1988. The information content of discount announcements and their effect on market interest rates. Journal of Money, Credit, and Banking 20: 167-180.

Cook, T., and Hahn, T. 1989. The effect of changes in the Federal funds rate target on market interest rates in the 1970s. Journal of Monetary Economics 24: 331-351.

Demiralp, S. 2001. Monetary policy in a changing world: Rising role of expectations and the anticipation effect. Finance and Economics Discussion Series (FEDS), paper \# 2001-55, The Federal Reserve Board. Washington, D.C.

Dueker, M. 1992. The response of market interest rates to discount rate changes. Federal Reserve Bank of St. Louis Review 74:78-91.

Flannery, M.J., and James, C.M. 1984. The effect of interest rate changes on the common stock returns of financial institutions. Journal of Finance 39: 1141-1153.

Hanweck, G.A. and Kilcollin, T. E. 1984. Bank profitability and interest rate risk. Journal of Economics and Business 36: 77-84.

Jensen, G.; Mercer, J.; and Johnson, R. 1996. Business condition, monetary policy and expected security returns. Journal of Financial Economics 40: 213-237. 
Judge et. al. 1988. Introduction To The Theory And Practice Of Econometrics. 2nd edition, John Wiley and Sons, New York, NY.

Kaen, R.K.; Sherman, H. C.; and Tehranian, H. 1997. The effects of Bundesbank discount and Lombard rate changes on German bank stocks. Journal of Multinational Financial Management 7: 1-25.

Kuttner, K.N. 2001. Monetary policy surprises and interest rates: Evidence from the Fed funds futures markets. Journal of Monetary Economics 47: $523-544$.

Lange, J.; Sack, B.; and Whitesell, W. 2001. Anticipations of monetary policy in financial markets, Finance and Economics Discussion Series (FEDS) paper \# 2001-24, The Federal Reserve Board. Washington, D.C.

Madura, J., and Schnusenberg, O. 2000. Effect of Federal Reserve policies on bank equity returns. Journal of Financial Research 23: 421-447.

Mankiw, N.G. 2001. U.S monetary policy during the 1990's. NBER Working Paper\# W8471, National Bureau of Economic Research, Cambridge, MA.

Mansur, I., and Elyasiani, E. 1995. Sensitivity of bank equity returns to the level and volatility of interest rates. Managerial Finance 21:57-77.

McQueen, G., and Roley, V.V. 1993. Stock prices, news, and business conditions. The Review of Financial Studies 6: 683-707.

Neuberger, J. A. 1991. Risk and return in banking: Evidence from bank stock returns. Federal Reserve Bank of San Francisco Economic Review Fall: $18-30$.

Park, K., and Ratti, R. 2000. Real activity, inflation, stock returns, and monetary policy. Financial Review 35: 59-78.

Patelis, A. 1997. Stock return predictability and the role of monetary policy. Journal of Finance 52: 1951-1972.

Roley, V.V., and Troll, R. 1984. The impact of discount rate changes on market interest rates. Federal Reserve Bank of Kansas City Economic Review January: 27-39.

Rudebusch, G., 1998. Do measures of monetary policy in a VAR make sense? International Economic Review 39: 907-931.

Smirlock, M., and Yawitz, J. 1985. Asset returns, discount rate changes, and market efficiency. Journal of Finance 40: 1141-1158.

Stevenson, S. 2002. The sensitivity of European bank stocks to German interest rate changes. Multinational Finance Journal 6: 223-249.

Symposia on the Monetary Transmission Mechanism. Journal of Economic Perspectives. Fall 1995. 9: 3-96.

Thorbecke, W. 1997. On stock market returns and monetary policy. Journal of Finance 52: 635-654.

Wachtel, P., and Urich, T. 2001 Financial market responses to monetary policy changes in the 1990's. SSRN Working Paper, Social Science Research Network.

White, H. 1980. A heteroskedasticity consistent covariance matrix estimator and a direct test of heterodkedasticity. Econometrica 48: 817-838. 